\title{
Antiviral Effects of Mandarin Somatid Natural Gel on SARS-CoV-2 Infection in vitro
}

\author{
Yeonhwa Kim, Eun Yong Oh, Sohyun Park, Sang-Myeong Lee* \\ College of Veterinary Medicine, Chungbuk National University, Cheongju 28644, Republic of Korea
}

\section{Corresponding}

Sang-Myeong Lee, DVM, Ph.D.

College of Veterinary Medicine,

Chungbuk National University,

Cheongju 28644, Republic of Korea

Phone : +82-43-261-3356

Fax : +82-43-267-3150

E-mail : smlee@chungbuk.ac.kr

Received : December 6, 2021

Revised : December 13, 2021

Accepted : December 14, 2021

No potential conflict of interest relevant to this article was reported.

Copyright (C) 2021 Journal of Bacteriology and Virology

(C) This is an Open Access article distributed under the terms of the Creative Commons Attribution Non-Commercial License

(http://creativecommons.org/

license/by-nc/3.0/).
Severe acute respiratory syndrome coronavirus 2 (SARS-CoV-2) was reported in Wuhan, China, in December 2019 and continues to spread worldwide. Although several vaccines were developed and are being used worldwide, antivirals are still needed for people who are not vaccinated or who are vaccinated but infected due to insufficient immune responses. Plant-derived natural substances have long been studied to develop drugs for infectious diseases, and accumulated evidences support a possibility that these may well be efficacious in reducing the risk of SARS-CoV-2 infection. In the present study, it was determined whether somatid natural gels (SNGs) prepared from mandarin, ginseng, or garlic inhibit the replication of SARS-CoV-2 in vitro study. Cytopathic effect (CPE) inhibition assay, immunofluorescence assay (IFA), and quantitative real-time polymerase chain reaction (qRT-PCR) were performed to evaluate the effect of SNGs on SARS-CoV-2 replication in cell culture. Among three SNGs, the mandarin SNG had the highest inhibitory effect on SARS-CoV-2-induced CPE, while the garlic SNG showed no activity. When viral protein levels were identified by IFA, mandarin SNG treatment suppressed $\mathrm{N}$ protein expression in a dose-dependent manner. In addition, viral RNA copy numbers and infectious viral titers of SARS-CoV-2 were also significantly reduced by mandarin SNG. Our results suggest that mandarin SNG exerts antiviral activities against SARS-CoV-2, implying a possible use of these natural materials as a preventive or therapeutic agent for COVID19.

Key Words: SARS-CoV-2, Somatid nature gel, Mandarin

\section{INTRODUCTION}

Severe acute respiratory syndrome coronavirus 2 (SARS-CoV-2) has caused a pandemic of coronavirus disease 2019 (COVID-19), leading to a global health crisis and significant economic loss $(1,2)$. Several vaccines had been developed and are being distributed quickly, hoping COVID-19 pandemic ends in the near future. Effective and affordable anti-virals are still necessary for patients who are not vaccinated or where vaccines fail to prevent COVID-19. Currently, various therapeutic candidates against SARS-CoV-2 are being developed and are being treated to people (3-6). Dexamethasone and Remdesivir are used for the treatment of SARS-CoV-2 (7). Dexamethasone is a corticosteroid drug with anti-inflammatory action. Dexamethasone is used as a steroid therapy to treat SARS-CoV-2 patients (8). Remdesivir is a viral RNA-dependent RNA polymerase inhibitor that has the ability to inhibit SARS-CoV-2 in vitro. Furthermore, patients treated with remdesivir 
recovered clinically faster than patients treated with placebo (9). Bamlanivimab and etesevimab were neutralizing monoclonal antibodies isolated from the serum of patients recovering from COVID-19 in the United States and China. In a recent study, the combination of bamlanivimab and etesevimab resulted in lower hospitalization and death rate than the placebo group (10). Although there are cases where drug repurposing and neutralizing monoclonal antibody have become therapeutic agents, a therapeutic agent for covid-19 derived from natural products is still being studied (11).

Plant extracts have been used as a medicine for a long time for various pharmacological purposes, including infectious diseases, and natural substances derived from plants can be safe and effective therapeutics for many diseases (12). Moreover, a number of scientific publications have encouraged the use of biological compounds derived from plants in the treatment and prophylaxis of diseases caused by microbial pathogens, including viruses. However, the investigations to develop therapeutics or prophylaxis for viral infection derived from plants are relatively limited in comparison with those for bacterial infection $(13,14)$. The medicinal or herbal plants, and their phytoconstituents, could be important sources for exploring novel alternative /supplementary treatments or prophylaxis for COVID-19. Recent studies demonstrated that various medicinal plants extracts, herbal extracts, and phytochemicals possess antiviral activities and can be used to prevent or treat COVID-19 $(15,16)$.

In order to investigate a possible antiviral activity, plant extracts are usually prepared by hot water, ethanol, or methanol extraction process. Here, we studied whether somatid natural gel (SNG), which is manufactured through the multistep process including mixing with water, heat treatment, aeration, centrifugation, and evaporation of garlic, mandarin fruit, and ginseng. Since SNG contains highly concentrated natural substances from the intermediate layer of centrifuged water/plant mixtures, it is possible that SNG has higher levels of bioactive materials compared to hot water prepared materials from the top layer. Joung $\mathrm{O}$ et al. demonstrated that a mixture of somatid from minerals and plant extracts possessed a potential to teat cervical cancer caused by human papilloma virus (HPV) (17). In the present study, we investigated whether SNG prepared from mandarin, garlic, or ginseng has antiviral effect on SARS-CoV-2 in Vero cell culture.

\section{MATERIALS AND METHODS}

\section{Somatid natural gel (SNG) preparation}

SNGs were prepared as described at Korean patent (KP) 10-1628995 and provided by Philsang Life Sciences Co., Ltd (18).

\section{Vero cell culture and SARS-CoV-2 infection}

Vero (African green monkey kidney epithelial) cells were maintained in Dulbecco's Modified Eagle's Medium 118 (DMEM) (Lonza, Basel, Switzerland) supplemented with 1\% penicillin/streptomycin solution (Sigma-Aldrich, Saint Louis, USA) and $10 \%$ fetal bovine serum (FBS) (Gibco, Waltham, USA). SARS-CoV-2 was provided by National Culture Collection for Pathogens (NCCP). To infect Vero cells with SARS-CoV-2, cells were incubated with SARS-CoV-2 for $1 \mathrm{~h}$ at $37^{\circ} \mathrm{C}$, in $5 \%$ $\mathrm{CO}_{2}$ incubator. Then, cell culture medium was removed and DMEM containing $2 \% \mathrm{FBS}$ and $1 \%$ penicillin/streptomycin solution was added.

\section{Plaque assay}

Vero cells in 12-well plates were treated with cell culture supernatant diluted step-wise by 10 -fold for $1 \mathrm{~h}$ at $37^{\circ} \mathrm{C}$, in $5 \%$ $\mathrm{CO}_{2}$ incubator. After washing with PBS, cells were overlaid with DMEM with $0.5 \%$ agarose (genDEPOT, Texas, USA). Cells were fixed in 10\% formaldehyde (Daejung, Siheung, Korea) for 10 min at 3 days post infection (dpi). Overlaid media was removed, and cells were stained with $0.4 \%$ crystal violet (Junsei, Tokyo, Japan) for $10 \mathrm{~min}$. Then, visible plaques were counted. 


\section{Cytotoxicity assay}

Mandarin, garlic, and ginseng SNGs were diluted to $10 \mathrm{mg} / \mathrm{ml}$ with DMEM and were filtered by $0.2 \mu \mathrm{m}$ syringe filter (CORNING, New York, USA). Vero cells in 96-well plates were treated with SNGs at various concentrations for $72 \mathrm{~h}$ at $37^{\circ} \mathrm{C}$, in $5 \% \mathrm{CO}_{2}$ incubator. Cell cytotoxicity was evaluated by using EZ-cytox kit (Dogenbio, Seoul, Korea).

\section{Cytopathic effect (CPE) inhibition assay}

The assessment of the anti-SARS-CoV-2 activity of the SNG was based on the evaluation of the inhibition of virus induced cytopathic effect (CPE) in Vero cells. Vero cells were seeded into 96-well plates and infected with SARS-CoV-2 at multiplicity of infection (m.o.i) 0.01 . After $1 \mathrm{~h}$, cells were treated with SNGs at various concentrations for $72 \mathrm{~h}$ at $37^{\circ} \mathrm{C}$, in $5 \% \mathrm{CO}_{2}$ incubator. Cells were fixed in $10 \%$ formaldehyde for $10 \mathrm{~min}$ and stained with $0.4 \%$ crystal violet for $10 \mathrm{~min}$. Crystal violet solution was removed and cells were washed with PBS. Crystal violet from remaining cells were eluted by methanol (Daejung, Siheung, Korea) and acetic acid (Daejung, Siheung, Korea) mixture (1:1) for $3 \mathrm{~h}$ at room temperature in a gentle rocker. Optical density was measured by spectrophotometer (BioTek, Winooski, USA) at $550 \mathrm{~nm}$. The CPE inhibition percentages were measured using the following equation: T-VC/CC-VC, where $T$ is the optical density (OD) of compound treated cells, VC is the OD of virus control, and CC is the OD of cell control (19).

\section{Immunofluorescence assay (IFA)}

Vero cells were cultured in an 8-well chamber slide and infected with SARS-CoV-2 at m.o.i 0.01 for $1 \mathrm{~h}$. After the virus was removed, cells were treated with the mandarin SNG for $16 \mathrm{~h}$ at $37^{\circ} \mathrm{C}$, in $5 \% \mathrm{CO}_{2}$ incubator. Then, cells were fixed with a mixture of acetone and methanol for 10 min. Fixated cells were washed with PBS twice and treated with $5 \%$ Normal goat serum (Abcam, Cambridge, UK) for blocking non-specific binding sites for $1 \mathrm{~h}$ at RT (Blocking). After washing with PBS twice, cells were incubated with anti-SARS CoV-2 nucleocapsid protein antibody (primary antibody) (SinoBiological, Beijing, China) overnight at $4^{\circ} \mathrm{C}$. Cells were stained with goat-anti-mouse 488 antibody (Jackson Laboratory, Bar Harbor, USA) for $1 \mathrm{~h}$ at RT. Cells were washed three times with buffer and mounted with Fluorescent Mounting Media (Dako, Glostrup, Denmark) and observed under fluorescence microscope (Olympus, Tokyo, Japan).

\section{qRT-PCR}

Viral RNA was extracted using the AccuPrep ${ }^{\circledR}$ Viral RNA Extraction Kit (Bioneer, Daejeon, Korea). Complementary DNA (CDNA) was synthesized by using Rever Tra ACE ${ }^{\circ}$ qPCR RT Kit (TOYOBO, Osaka, Japan). qRT-PCR was performed using AccuPower ${ }^{\circledR}$ GreenStar ${ }^{\top M}$ RT-qPCR Master Mix (Bioneer, Daejeon, Korea). Viral RNA copy numbers were calculated using the SARS-CoV-2 RNA standard sample. Synthesized CDNA from viral RNA with a CDNA synthesis kit (TOYOBO, Osaka, Japan) were used to make standard samples. PCR amplification kit (Invitrogen, Waltham, USA) and PCR clean up kit (Promega, Madison, USA) were used for amplification and clean up. TOPspeed ${ }^{\text {TM }}$ DNA Ligation kit (Promega, Madison, USA) was used for ligation, and transformation was performed using DH5-alpha competent cell (Enzynomics, Daejeon, Korea). The following primers were used: Receptor-Binding Domain (RBD) Forward: 5'-CAA TGG TTT AAC AGG CAC AGG-3', RBD reverse: 5'-CTC AAG TGT CTG TGG ATC ACG-3', RBD Forward for standard : 5'-GCT CCA TGG CCT AAT ATT ACA AAC TTG TGC C-3', and RBD reverse for standard: 5'-TGC TCT AGA CTC AAG TGT CTG TGG ATC AC-3' (20).

\section{Flavonoids contents analysis}

Flavonoids contents of mandarin SNG were analyzed at Jeju Special Self-Governing Province Agricultural Research and Extension Service as described previously (21). 


\section{Data analysis}

Statistical analysis was performed using GraphPad Prism. Data were expressed as mean with standard error of the mean (SEM). Analysis was performed using a one-way ANOVA with Tukey's Multiple Comparison Test.

\section{RESULT}

\section{Cytotoxicity evaluation of mandarin, garlic, and ginseng SNGs}

Cell viability was measured by performing MTT assay to evaluate the toxicity of mandarin, garlic, and ginseng SNGs. Three types of SNGs were diluted serially 10 -fold from $10 \mathrm{mg} / \mathrm{ml}$ to $0.078 \mathrm{mg} / \mathrm{ml}$ and added into Vero cells. As shown in Fig. 1 , mandarin and garlic SNGs did not show cytotoxicity at all concentrations. However, ginseng SNG showed over $20 \%$ cytotoxicity at $1.25,2.5,5$, and $10 \mathrm{mg} / \mathrm{ml}$ (Fig. 1B).

\section{Mandarin SNG inhibits the CPE induced by SARS-CoV-2}

CPE inhibition assay was performed to evaluate whether the three types of SNG inhibit SARS-CoV-2 replication in Vero cell cultures. Cells in 96 well plates were treated with mandarin or garlic SNG at concentrations ranging from 0.078 to 10 $\mathrm{mg} / \mathrm{ml}$ and ginseng SNG at concentrations ranging from 0.078 to $2.5 \mathrm{mg} / \mathrm{ml}$ (Fig. 2). The mandarin SNG significantly inhibited CPE caused by SARS-CoV-2 replication at $0.312 \mathrm{mg} / \mathrm{ml}$ or higher $(\mathrm{p}<0.05)$. Cells treated with $2.5 \mathrm{mg} / \mathrm{ml}$ or higher mandarin SNG showed an O.D. value similar to that of the control (Fig. 2-A2). In addition, ginseng SNG treatment suppressed SARS-CoV-2 replication at over $0.156 \mathrm{mg} / \mathrm{ml}$ ( $p<0.05$, Fig. 2-B2). However, it did not block 100\%; because of cytotoxicity at 1.25 to $2.5 \mathrm{mg} / \mathrm{ml}$, cell viability appears to be lower than that of $0.625 \mathrm{mg} / \mathrm{ml}$ treated group (Fig. 1B, Fig. 2-B2). Garlic SNG did not inhibit CPE by SARS-CoV-2 replication at all (Fig. 2-C2).

\section{Mandarin SNG inhibits expression of nucleocapsid protein}

IFA was performed on mandarin SNG that showed an effect of inhibiting CPE by SARS-CoV-2 replication. The protein expression of SARS-CoV-2 was significantly reduced in the group treated with mandarin SNG at $2.5 \mathrm{mg} / \mathrm{ml}$ compared to the group without mandarin SNG (Fig. 3). In the other concentrations, the protein expression decreased in a concentrationdependent manner (Fig. 3).
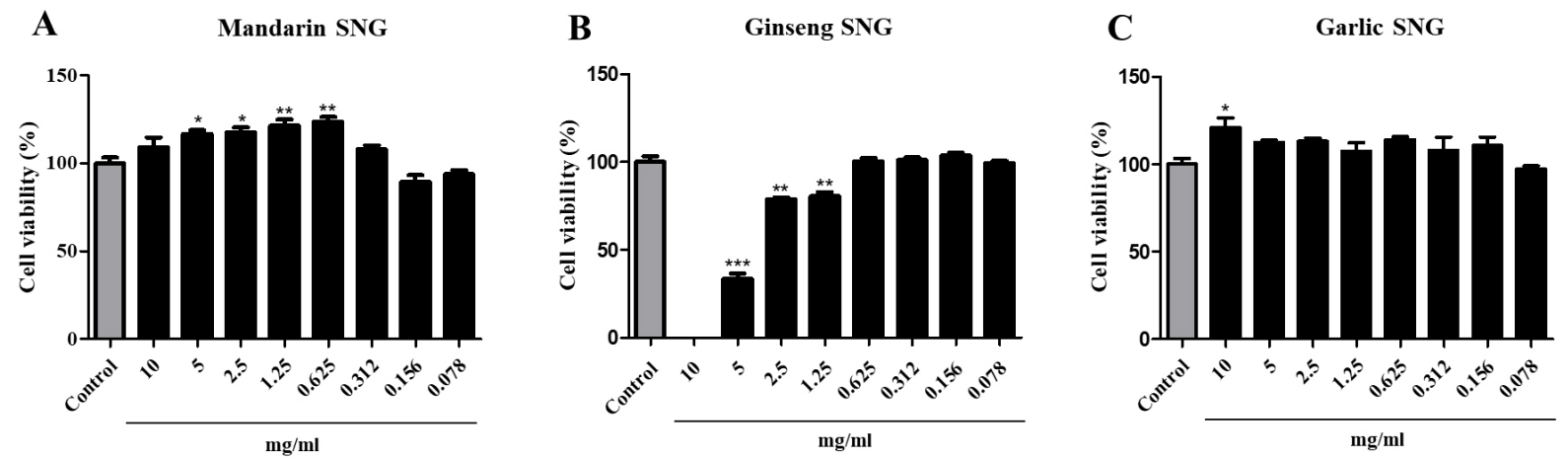

Fig. 1. Cell viability of mandarin, garlic, and ginseng SNGs. Vero cells were cultivated in 96-well plate (flat). Three types of SNGs were diluted stepwise by 2-fold from 0.078 to $10 \mathrm{mg} / \mathrm{ml}$ and were treated in cells for $3 \mathrm{~h}$. Values are expressed as Mean \pm SEM. The different superscripts denote differences at $* p<0.05, * * p<0.01$ and $* * * p<0.001$. 

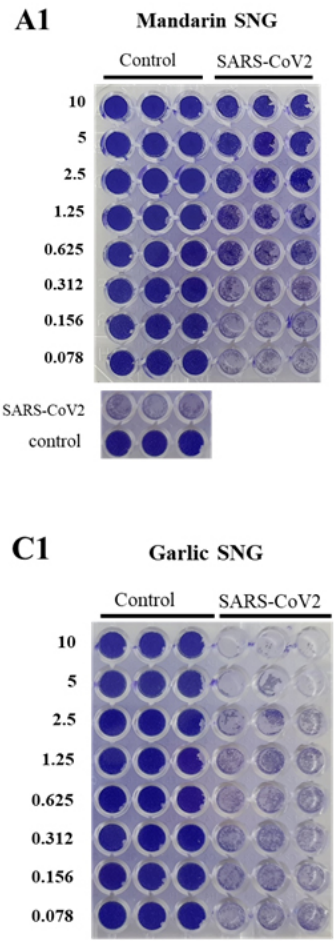
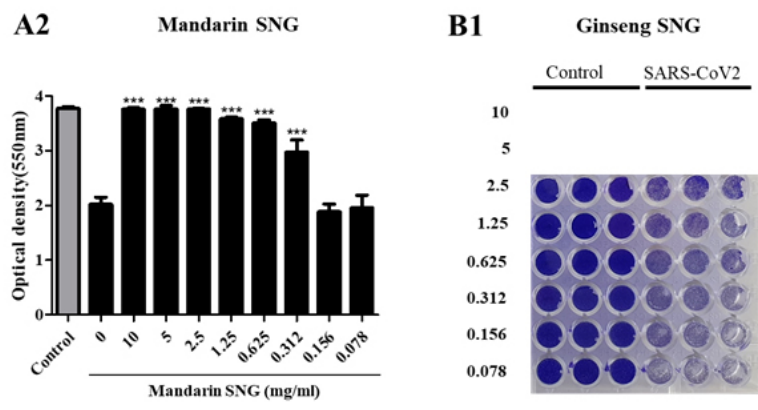

B2 Ginseng SNG

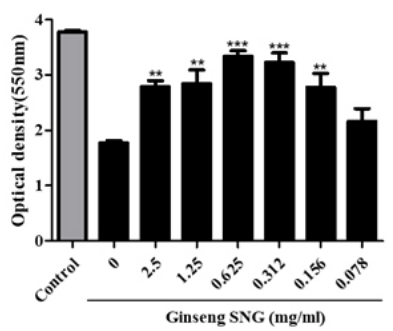

C2

Garlic SNG

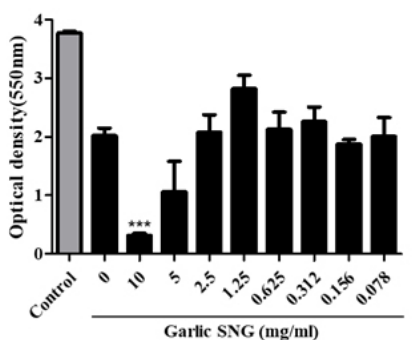

Fig. 2. Inhibitory effect of mandarin, ginseng, and garlic SNGs on CPE by SARS-CoV-2 replication. Infected Vero cells were incubated for $1 \mathrm{~h}$ with three types of SNGs of serially diluted concentration. Virus was treated with virus of m.o.i 0.01. After incubation for $72 \mathrm{~h}$, cells were fixed in 10\% formaldehyde and decolorized by Methanol/Acetic acid. Optical density was measured using a spectrophotometer. Values are expressed as Mean \pm SEM. The different superscripts denote differences at $* \star p<0.01, * * * p<0.001$.

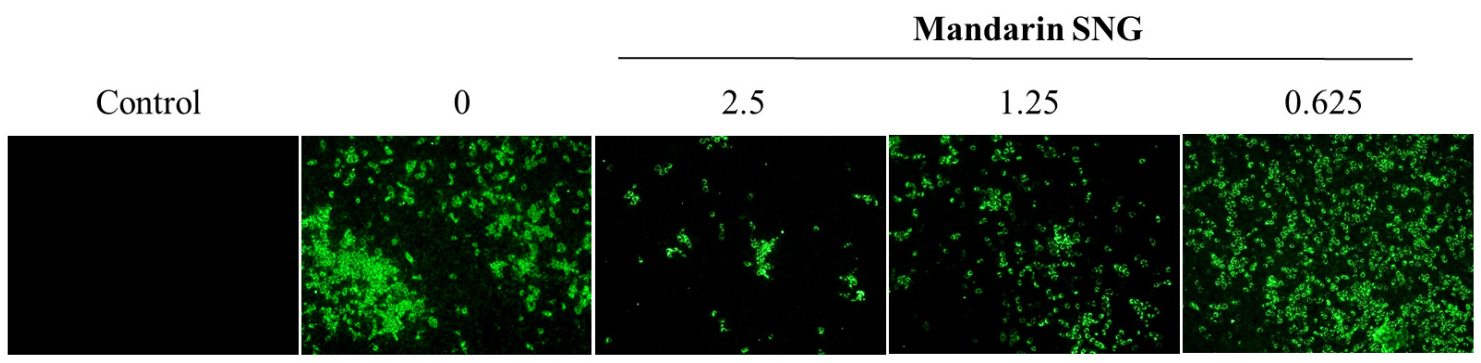

Fig. 3. Inhibitory effect of mandarin SNG on the expression of SASR-CoV-2 N-protein. Vero cells were treated with mandarin SNG of serially 2 -fold diluted concentration from 0.625 to $2.5 \mathrm{mg} / \mathrm{ml}$. Cells were fixed with cold acetone/methanol solution and stained with anti-SARS-CoV-2 nucleocapsid protein antibody with secondary antibody conjugated with FITC.

\section{Inhibitory activity of mandarin SNG on SARS-CoV-2 replication}

qRT-PCR was conducted to determine the effect of mandarin SNG treatment on the expression of SARS-CoV-2 gene (Fig. $4 A$ ), and plaque assay was conducted to confirm the inhibition of SARS-CoV-2 replication by measuring the amount of infectious virus released to the outside of the cell (Fig. 4B). When the mandarin SNG was treated in Vero cells at $2.5 \mathrm{mg} / \mathrm{ml}$ or higher, it was confirmed that the gene expression of SARS-CoV-2 was significantly reduced (Fig. 4B). In addition, when the mandarin SNG was treated in cells at $2.5 \mathrm{mg} / \mathrm{ml}$ or higher, it was confirmed that the amount of virus was reduced by $90 \%$ or higher (Fig. 4B). 
A

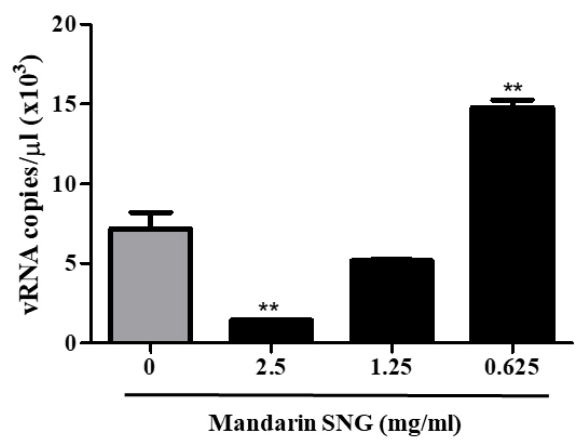

B

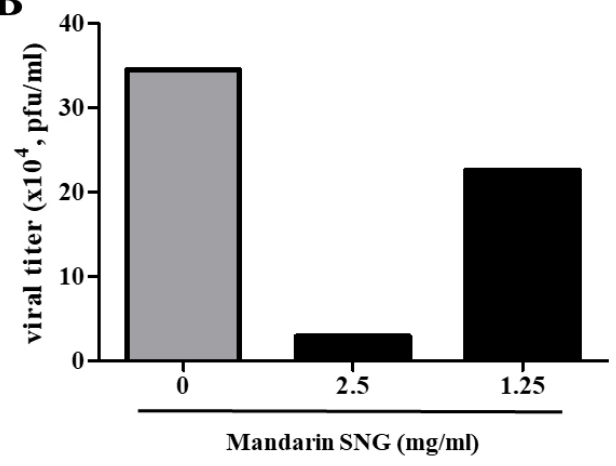

Fig. 4. Inhibitory activity of mandarin SNG on SARS-CoV-2 replication. Vero cells were treated with mandarin SNG of diluted concentration from 0.625 to $2.5 \mathrm{mg} / \mathrm{ml}$. Figure A shows the amount of SARS-CoV-2 RNA from Vero cells treated with mandarin SNG by qRT-PCR, and figure B shows the amount of SARS-CoV-2 in the cell supernatant treated with mandarin SNG by plaque assay. Values are expressed as Mean \pm SEM (Fig4-A). The different superscripts denote differences at $* * p<0.01$ (Fig. 4-A).

Table 1. Flavonoid components of mandarin SNG

Flavonoid content (ppm, mg/kg)

Flavonoid ingredients

Repeats $1 \quad$ Repeats $2 \quad$ Average

\begin{tabular}{cccc}
\hline Narirutin & $6,413.9$ & $6,483.8$ & $6,448.8$ \\
Hesperidin & $5,286.6$ & $5,163.2$ & $5,224.9$ \\
Naringenin & 26.7 & 24.6 & 25.7 \\
Hesperetin & 22.6 & 24.2 & 23.4 \\
Noviletin & 90.0 & 94.5 & 92.3 \\
Tangeletin & 48.5 & 53.5 & 51.0 \\
Sinensetin & 9.0 & 9.1 & 9.1 \\
\hline
\end{tabular}

\section{Flavonoids composition of mandarin SNG}

Flavonoids are the main components of plant polyphenols which are well-known bioactive agents (22). In order to see which flavonoid could be the major component of mandarin SNG, we analyzed flavonoids content in mandarin SNG and found that narirutin and hesperidin were the two most common (Table 1).

\section{DISCUSSION}

SARS-CoV-2 has been prevalent globally since its outbreak in Wuhan, China (23). In order to suppress the SARS-CoV-2 pandemic, it is essential to develop not only a vaccine but also a therapeutic agent (24). Plant-derived natural substances have been studied as therapeutic candidates (12), and recent studies have shown that several natural extracts are effective in the inhibition of SARS-CoV-2. Platycodin D, a natural component of Platycodon grandiflorum, is known to inhibit the invasion of SARS-CoV-2 into cells by interfering with membrane fusion (25). Glycyrrhizin, an extract of licorice, inhibits SARS-CoV-2 replication by inhibiting the viral main protease $M^{\text {pro }}(26)$. Epigallocatechin Gallate, abundant in green tea, is 
studied to inhibit Nsp15 of SARS-CoV-2 (27). In the present study, we demonstrated that mandarin SNG effectively inhibits SARS-CoV-2 replication in vitro.

A potential beneficial effect of citrus fruit extracts were widely studied, and a recent review highlighted the potential benefits of citrus fruit components for therapeutics or prophylaxis for viral infections such as COVID-19 (28). It is well known that citrus fruits are rich of vitamins and flavonoids. Among the flavonoids, hesperidin has been reported that it inhibits influenza virus (29). Haggag et al. suggested the hesperidin could be useful for prophylactic purpose and therapeutic of SARS-CoV-2 (30) and a molecular docking study by Joshi et al. demonstrated that hesperidin may strongly bind to SARS-COV-2 protease and angiotensin-converting enzyme 2 (ACE-2) (31), suggesting that hesperidin may have anti-viral activity on SARS-CoV-2. A recent study by Kandeil et al. showed hesperidin possesses the virucidal effect as well as viral replication inhibitory effect (32). Antiviral effect of hesperidin was also demonstrated in mice infected with encephalomyocarditis virus (33). In the present study, we clearly demonstrated that SNG prepared from mandarin, one of major citrus fruits consumed in Korea, suppressed SARS-CoV-2 replication and this antiviral effect could be mediated by hesperidin which is a major flavonoids component of mandarin SNG.

In conclusion, we demonstrated the anti-viral activity of mandarin SNG on SARS-CoV-2 in vitro, and this result provides a potential use of these materials to prevent or treat COVID-19. However, further in-depth studies are necessary to define molecular mechanisms by which mandarin SNG suppresses SARS-CoV-2. In addition, in vivo studies using COVID-19 animal models are essential to prove its antiviral effects on SARS-CoV-2.

\section{ACKNOWLEDGEMENTS}

This study was financially supported by Philsang Life Sciences Co., Ltd., Bongdong-eup, Wanju-gun, Jeonbuk, Republic of Korea.

\section{CONFLICT OF INTEREST}

No potential conflicts of interest relevant to this article were reported.

\section{REFERENCES}

1) Sohrabi C, Alsafi Z, O'Neill N, Khan M, Kerwan A, Al-Jabir A, et al. World Health Organization declares global emergency: A review of the 2019 novel coronavirus (COVID-19). Int J Surg 2020;76:71-6.

2) Keogh-Brown MR, Smith RD. The economic impact of SARS: How does the reality match the predictions? Health Policy 2008;88:110-20.

3) Castells MC, Phillips EJ. Maintaining Safety with SARS-CoV-2 Vaccines. N Eng/ J Med 2021;384:643-9.

4) Sharun $K$, Dhama $K$, Patel SK, Pathak M, Tiwari R, Singh BR, et al. Ivermectin, a new candidate therapeutic against SARS-CoV-2/COVID-19. Ann Clin Microbiol Antimicrob 2020:19:23.

5) Xiao $X$, Wang $C$, Chang D, Wang $Y$, Dong $X$, Jiao $T$, et al. Identification of Potent and Safe Antiviral Therapeutic Candidates Against SARS-CoV-2. Front Immuno/2020;11:586572.

6) Park SJ, Yu KM, Kim Y II, Kim SM, Kim EH, Kim SG, et al. Antiviral efficacies of FDA-approved drugs against SARS-COV-2 infection in ferrets. MBio 2020;11:e01114-20. 
7) Jean SS, Lee PI, Hsueh PR. Treatment options for COVID-19: The reality and challenges. J Microbiol Immunol Infect 2020;53:436-43.

8) Noreen S, Maqbool I, Madni A. Dexamethasone: Therapeutic potential, risks, and future projection during COVID-19 pandemic. EurJ Pharmaco/2021:894:173854.

9) Beigel JH, Tomashek KM, Dodd LE, Mehta AK, Zingman BS, Kalil AC, et al. Remdesivir for the Treatment of Covid-19 - Final Report. N Eng/ J Med 2020;383:1813-26.

10) Dougan M, Nirula A, Azizad M, Mocherla B, Gottlieb RL, Chen P, et al. Bamlanivimab plus Etesevimab in Mild or Moderate Covid-19. N Eng/J Med 2021;385:1382-92.

11) Babaei F, Mirzababaei $M$, Nassiri-Asl $M$, Hosseinzadeh $H$. Review of registered clinical trials for the treatment of COVID-19. Drug Dev Res 2021:82:474-93.

12) Bhuiyan FR, Howlader S, Raihan T, Hasan M. Plants Metabolites: Possibility of Natural Therapeutics Against the COVID-19 Pandemic. Front Med 2020;7:444.

13) Mukhtar M, Arshad M, Ahmad M, Pomerantz RJ, Wigdahl B, Parveen Z. Antiviral potentials of medicinal plants. Virus Res 2008:131:111-20.

14) Lin LT, Hsu WC, Lin CC. Antiviral natural products and herbal medicines. J Tradit Complement Med 2014:4:24-35.

15) Islam R, Parves MR, Paul AS, Uddin N, Rahman MS, Mamun A Al, et al. A molecular modeling approach to identify effective antiviral phytochemicals against the main protease of SARS-CoV-2. J Biomol Struct Dyn 2021:39:3213-24.

16) Huang F, Li Y, Leung EL, Liu X, Liu K, Wang Q, et al. A review of therapeutic agents and Chinese herbal medicines against SARS-COV-2 (COVID-19). Pharmacol Res 2020;158:104929.

17) Joung O, Cho YS, Cho CW, Lee KA, Shim JH, Cho MC, et al. The Effects of Somatid on the Cytotoxicity of Cancer Cells and Human Papillomavirus Type 16 E6 and E7 Oncogenes. YAKHAK HOEJ/2000;44:340-6.

18) Lee JD. Natural extracts, and natural somatid gel method and a multi-functional material powder prepared using the same composition. Korean patent KR 10-1628995. 2016 Jun 9.

19) Schmidtke $M$, Schnittler $U$, Jahn $B$, Dahse $H$, Stelzner A. A rapid assay for evaluation of antiviral activity against coxsackie virus B3, influenza virus A, and herpes simplex virus type 1. J Virol Methods 2001:95:133-43.

20) Amporndanai $K$, Meng $X$, Shang $W$, Jin $Z$, Rogers $M$, Zhao $Y$, et al. Inhibition mechanism of SARS-CoV-2 main protease by ebselen and its derivatives. Nat Commun 2021:12:3061.

21) Park YC, Yang YT, Kim JY, Lee $\mathrm{CH}$, Kang SH, Kang JH, et al. Characteristics of Flavonoids in Juice and Cluster Analysis of Satsuma Mandarin Germplasms. Korean J Plant Resour 2015;28:16-25.

22) Tungmunnithum D, Thongboonyou A, Pholboon A, Yangsabai A. Flavonoids and Other Phenolic Compounds from Medicinal Plants for Pharmaceutical and Medical Aspects: An Overview. Medicines 2018:5:93.

23) Chan JFW, Yuan S, Kok KH, To KKW, Chu H, Yang J, et al. A familial cluster of pneumonia associated with the 2019 novel coronavirus indicating person-to-person transmission: a study of a family cluster. Lancet 2020;395:514-23.

24) Chen N, Zhou M, Dong X, Qu J, Gong F, Han Y, et al. Epidemiological and clinical characteristics of 99 cases of 2019 novel coronavirus pneumonia in Wuhan, China: a descriptive study. Lancet 2020;395:507-13.

25) Kim TY, Jeon S, Jang Y, Gotina L, Won J, Ju YH, et al. Platycodin D, a natural component of Platycodon grandiflorum, prevents both lysosome- and TMPRSS2-driven SARS-CoV-2 infection by hindering membrane fusion. Exp Mol Med 2021:53:956-72. 
26) van de Sand L, Bormann M, Alt M, Schipper L, Heilingloh CS, Steinmann E, et al. Glycyrrhizin effectively inhibits sars-cov-2 replication by inhibiting the viral main protease. Viruses 2021;13:609.

27) Hong S, Seo SH, Woo SJ, Kwon Y, Song M, Ha NC. Epigallocatechin Gallate Inhibits the Uridylate-Specific Endoribonuclease Nsp15 and Efficiently Neutralizes the SARS-CoV-2 Strain. J Agric Food Chem 2021;69:5948-54

28) Bellavite P, Donzelli A. Hesperidin and SARS-CoV-2: New light on the healthy function of citrus fruits. Antioxidants 2020;9:742.

29) Dong W, Wei X, Zhang F, Hao J, Huang F, Zhang C, et al. A dual character of flavonoids in influenza A virus replication and spread through modulating cell-autonomous immunity by MAPK signaling pathways. Sci Rep 2014:4:7237.

30) Haggag YA, El-Ashmawy NE, Okasha KM. Is hesperidin essential for prophylaxis and treatment of COVID-19 Infection? Med Hypotheses 2020;144:109957.

31) Joshi RS, Jagdale SS, Bansode SB, Shankar SS, Tellis MB, Pandya VK, et al. Discovery of potential multi-target-directed ligands by targeting host-specific SARS-CoV-2 structurally conserved main protease. J Biomo/ Struct Dyn 2020;39:3099-114.

32) Kandeil A, Mostafa A, Kutkat O, Moatasim Y, Al-karmalawy AA, Rashad AA, et al. Bioactive polyphenolic compounds showing strong antiviral activities against severe acute respiratory syndrome coronavirus 2. Pathogens 2021;10:758.

33) Panasiak W, Wleklik M, Oraczewska A, Luczak M. Influence of flavonoids on combined experimental infections with EMC virus and Staphylococcus aureus in mice. Acta Microbiol Pol 1989;38:185-8. 